\section{Prognostic value for immediate function of one-hour renal allograft biopsy}

Transplanted cadaver kidneys, in contrast to renal homografts from living donors, may not function for a considerable time due to nonimmunological damage during collection and preservation. Knowledge of the degree of kidney damage when transplanted could influence the management of early oliguria or anuria after transplantation, and help to differentiate immunological from non-immunological causes. In this study biopsy specimens of transplanted kidneys, taken within one hour of revascularisation, were examined to evaluate the histological features which may be correlated with post-transplant anuria requiring dialysis.

\section{Methods and results}

Biopsy specimens from 50 transplanted cadaver kidneys were available through Eurotransplant to the Academic Hospital, Rotterdam. Forty kidneys were preserved by a non-pulsatile method (NP). Mean ischaemia time was 13 h 2 min (range 4 h 6 min-25 h $9 \mathrm{~min}$ ). Ten kidneys were preserved by a pulsatile method (P). Mean preservation time was $12 \mathrm{~h} 50 \mathrm{~min}$ (range 6 h 5 min-24 h $59 \mathrm{~min}$ ).

The transplanted kidneys were biopsied 30 to 60 minutes after revascularisation. One-half of each specimen was used for light microscopy using conventional staining methods, the other for immunofluorescence studies. Six biopsies were studied by light microscopy alone.

The biopsies were assessed blind and later correlated with the dialysis requirements till renal function occurred. The characteristics evaluated were the severity of glomerular and tubular damage, the degree of glomerular and peritubular polymorphonuclear leukocyte (PMN) infiltration, and interstitial oedema. The interstitial oedema was graded on an arbitrary scale 0 , ,+++ , and +++ , the grade being: 0 no oedema, + mild focal oedema, ++ moderate diffuse oedema, and $++t$ severe oedema. Comparisons were made between NP and P kidneys.

No relationship was found in the NP kidneys between the dialysis requirements and peritubular PMN infiltration or tubular lesions such as swelling and ballooning of cells, shedding of cells into the lumen, or nuclear loss. Glomerular PMN infiltration on glomerular lesions such as mesangial swelling or collapse of capillary loops also had no correlation with early function. The most significant feature was the occurrence of interstitial oedema (see table). All patients requiring more than five dialyses had severe interstitial oedema in their initial biopsy specimen. Only eight patients whose initial specimen showed any interstitial oedema had immediate renal function, and in only three of these was it as much as ++ (see table). There was also good correlation in the P kidneys between the amount of interstitial oedema and post-transplant dialysis requirements, but the number of kidneys was small (10). Immunofluorescence studies were of no prognostic significance.

Distribution of interstitial oedema and dialysis requirements in non-pulsatile perfused (NP) kidneys

\begin{tabular}{|c|c|c|c|c|}
\hline \multirow{2}{*}{$\begin{array}{l}\text { Interstitial } \\
\text { oedema }\end{array}$} & \multicolumn{4}{|c|}{$\begin{array}{l}\text { Numbers of patients needing haemodialysis } \\
\text { after transplantation }\end{array}$} \\
\hline & 0 & 1-5 Times & $>5$ Times & Total \\
\hline $\begin{array}{l}0 \\
+ \\
++ \\
+++\end{array}$ & $\begin{array}{r}11 \\
5 \\
3 \\
0\end{array}$ & $\begin{array}{l}1 \\
8 \\
3 \\
0\end{array}$ & $\begin{array}{c}0 \\
1^{*} \\
3^{*} \\
5\end{array}$ & $\begin{array}{r}12 \\
14 \\
9 \\
5\end{array}$ \\
\hline Total & 19 & 12 & 9 & 40 \\
\hline
\end{tabular}

*One patient in each group had a non-functioning transplanted kidney removed because of infection.

\section{Discussion}

Kincaid-Smith et al $^{1}$ found that the long-term prognosis of transplanted kidneys could be related to the number of PMNs in the glomeruli in early biopsy specimens. Perloff et $a l^{2}$ and Millard et $a l^{3}$ could find no such relationship. All these investigators, however, attempted to correlate the early histological changes with subsequent immunological events to determine which changes might be significant prognostically as regards rejection episodes and long-term prognosis.

We were interested in assessing whether any information could be obtained from the immediate post-transplant biopsy by which the duration of the oliguric period after transplantation could be anticipated. No correlation could be found between glomerular changes or $P M N$ infiltration and immediate impaired renal function after transplantation. Most biopsy specimens showed varying degrees of tubular degeneration but tubular changes without interstitial oedema did not appear to influence the need for prolonged dialysis.

A good correlation was obtained between interstitial oedema and the dialysis requirements regardless of the duration or method of preservation. That perseverance with prolonged dialysis in cases showing interstitial oedema is worth while is shown by the fact that these kidneys ultimately functioned well.

Dr K M Hawking is a recipient of the Gillson Scholarship in Pathology, Society of Apothecaries of London.

${ }^{1}$ Kincaid-Smith, P, et al, Lancet, 1968, 2, 748

2 Perloff, L J, et al, Lancet, 1973, 2, 1294.

${ }^{3}$ Millard, P R, Herbertson, B M, and Evans, D B, Lancet, 1970, 2, 113.

Departments of Pathology, Medicine, and Surgery, Academisch Ziekenhuis, Rotterdam, Netherlands

I W MCDICKEN, MB, MRCPATH, pathologist

K M HAWKING, MB, physician

L D F LAMEYER, MD, physician

A P R BLOK, MD, pathologist

D L WESTBROEK, MD, surgeon

\section{Primary spontaneous pneumothorax and smoking}

A spontaneous pneumothorax is called primary or idiopathic when occurring in apparently healthy people, usually young men aged $15-40 .{ }^{1}$ Although radiographic signs of lung disease are absent one or more cystic lesions (blebs or bullae) are usually found in the top of the lung, of ten bilaterally, at operation or necropsy. Rupture of one of these lesions may be the cause of the pneumothorax. A congenital defect or an acquired lesion secondary to localised stress, injury, or degenerative changes have been suggested as the pathogenetic mechanisms in these cystic lesions." Because most of our patients with primary spontaneous pneumothorax were heavy smokers and no conclusive data were available we compared the smoking habits of 44 consecutive patients with primary spontaneous pneumothorax with those of other patients and normal people.

\section{Methods and results}

We studied 44 consecutive men (group 1) who were admitted with primayspontaneous pneumothorax in 1966-73. There was no evidence of emphry sema, cysts, bullae, or other radiographic abnormalities apart from the pneumothorax. No patient had been treated for chronic obstructive lung disease or asthma. Group 2 consisted of 44 men aged 18-40 years with several types of diseases except those which might be related to smoking who were treated at the same time. Patients with chronic obstructive lung disease, ischaemic heart disease, or gastroduodenal disease were excluded. Group 3 consisted of 489 normal men aged 18-40 years. All subjects were asked how much tobacco (in cigarettes, cigars, or pipes) they smoked. Smokers were understood to be people who smoked at least one cigarette (or $1 \mathrm{~g}$ of tobacco) a day for one year. Ex-smokers were those who had stopped smoking at least a month earlier.

Over $90 \%$ of the patients with primary spontaneous pneumothorax (group 1) admitted to smoking five or more cigarettes a day, which was much more than patients in group $2(54 \%)$ or $3(53 \%)$ (see table). Especially heavy smoking ( $>15$ cigarettes/day) was more common in group $1(66 \%)$ than in group $2(36 \%)$ or $3(33 \%)$. The mean cigarette consumption $( \pm S D)$ in group $1(17 \pm 8)$ was considerably higher than in $2(10 \pm 10)$ or 3 (10 \pm 11 ). In group 1 only two patients (both aged 18 ) had never smoked before; one of them had oligophrenia. There was no reason to suppose that patients with primary spontaneous pneumothorax had exaggerated their smoking habits.

\section{Discussion}

It is difficult to compare the smoking habits of a group of patients 
Smoking habits of patients with primary spontaneous pneumothorax (group 1), other patients (group 2), and normal people (group 3). Results are numbers (percentages) of patients

\begin{tabular}{|c|c|c|c|c|c|c|c|c|c|c|}
\hline & \multirow{2}{*}{$\begin{array}{c}\text { No of } \\
\text { subjects }\end{array}$} & \multirow{2}{*}{$\begin{array}{c}\text { Mean }( \pm S D) \\
\text { age (years) } \\
\text { (range) }\end{array}$} & \multirow{2}{*}{ Non-smokers } & \multirow{2}{*}{ Ex-smokers } & \multirow{2}{*}{$\begin{array}{l}\text { Pipe and } \\
\text { cigar } \\
\text { smokers }\end{array}$} & \multicolumn{4}{|c|}{ Cigarettes per day } & \multirow{2}{*}{$\begin{array}{c}\text { Mean cigarette } \\
\text { consumption } \\
\text { (No/day)* }\end{array}$} \\
\hline & & & & & & $1-4$ & $5-14$ & $15-24$ & $>25$ & \\
\hline Group 1 & 44 & $26 \pm 6$ & $2(5)$ & $1(2)$ & $0(0)$ & $1(2)$ & $11(25)$ & $21(48)$ & $8(18)$ & $17 \pm 8$ \\
\hline Group 2 & 44 & $\begin{array}{l}(16-45) \\
27 \pm 6 \\
(18-39\end{array}$ & $14(32)$ & $1(2)$ & $2(5)$ & $3(7)$ & $8(18)$ & $12(27)$ & $4(9)$ & $10 \pm 10$ \\
\hline Group 3 & 489 & $\begin{array}{l}(18-39) \\
29 \pm 6 \\
(18-39)\end{array}$ & $105(22)$ & $84(17)$ & $20(4)$ & $17(3)$ & $100(20)$ & $99(20)$ & $64(13)$ & $10 \pm 11$ \\
\hline
\end{tabular}

*Based on assumption that mean cigarette consumption was 0 in non-smokers, ex-smokers, and pipe and cigar smokers and $29 \frac{1}{2}$ in people smoking $>25$ cigarettes a day.

with those of the normal population. Our control group (2) showed a pattern of cigarette consumption similar to that of the normal population (group 3) except for the ex-smokers. Probably most exsmoker patients called themselves non-smokers because no special question was posed on their former smoking habits.

Though in our series patients with apparent lung disease were not included the smoking habits of our patients agreed with those of Zivy's patients : only two of their patients had never smoked, two were ex-smokers, 35 smoked more than five cigarettes a day, and 27 admitted smoking more than 15 cigarettes a day.

Our data show that patients with primary spontaneous pneumothorax smoke considerably more than normal people. Thus heavy smoking is probably important in the aetiology of primary spontaneous pneumothorax although it is not the only factor. The relation between heavy smoking and primary spontaneous pneumothorax does not exclude an inherited predisposition to this condition. The preponderance of men $(85-95 \%)$ with primary spontaneous pneumothorax ${ }^{2}$ cannot merely be explained by thei heavier smoking habits; in Holland $60 \%$ of the men and $40 \%$ of the women are regular smokers. ${ }^{.}$Differences in mechanical forces in the lung between men and women may be important. ${ }^{5}$ As heavy smokers form a high risk group for spontaneous pneumothorax, patients with this condition who smoke should be strongly advised to stop.

We thank W H Doesburg and V Lauret for their statistical advice, C R Layton for his critical remarks, and $R$ van der Lende, head of the Research Unit for Epidemiology of CNSLD of the Organisation for Health Research TNO, the Netherlands, for help in selecting group 3.

1 Killen, D A, and Gobbel, W G, Spontaneous Pneumothorax. Boston, Little, Brown and Company, 1968.

2 British Medical fournal, 1968, 1, 720

${ }^{3}$ Zivy, P, Revue de Tuberculose et de Pneumologie, 1970, 34, 125.

4 Haas, J H de, Hartbulletin, 1973, 4, 77.

5 British Medical fournal, 1971, 4, 573.

Department of Pulmonary Diseases, St Radboud Hospital, University of Nijmegen, Netherlands

C A F JANSVELD, MD, chest physician (present address: Catharina Hospital, Eindhoven, Netherlands)

J H DIJKMAN, MD, associate professor of medicine

\section{High density polyethylene plate for fracture fixation in the elderly}

Screws are often difficult to fix firmly in osteoporotic bone. A plate applied to the bone shaft may distract from the cortex as the screws loosen and the fracture will be displaced. Any operation for a broken leg in an elderly patient must allow for immediate mobilisation ${ }^{1}$ and therefore an internal fixation is required which remains firmly in position when the limb is used.

\section{Material and method}

The plate is of high density polyethylene $3 \mathrm{~mm}$ thick, $1.8 \mathrm{~cm}$ wide, and varying in length from 2 to $16 \mathrm{~cm}$. It is curved in its transverse axis to lie

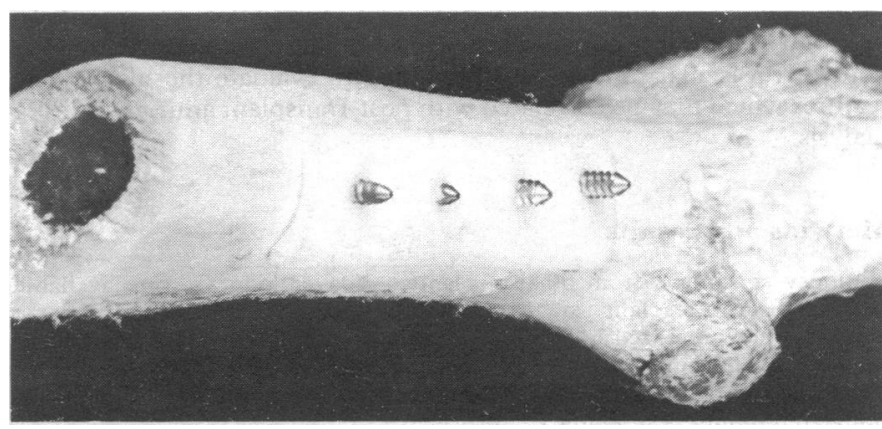

Cadaver specimen showing plate conforming to shape of bone when screws are tightened.

against the shaft of a long bone and has a radio-opaque marker in each of its four corners. The plates are individually packed and sterilised by $\gamma$ irradiation.

The bone is drilled in the normal manner and the drill passed through the polyethylene plate, which has been applied to the far cortex and held against the shaft of the bone with bone holders to prevent it from being pushed away from the cortex as drilling proceeds. A screw is then screwed through the metal plate and the bone to engage in the polyethylene plate, the thickness of which allows the thread of the screw to be firmly engaged while at the same time it will bend to adapt to the contour of the bone (see fig). As the screws are tightened the plate tends to flatten in its transverse axis, thus giving rise to some compression between the plate and bone cortex.

Laboratory tests showed that a butiress-thread screw pulled out of the polyethylene plate when a distraction force of $111 \mathrm{lb}(50.5 \mathrm{~kg})$ was applied. In the case of a self-tapping screw a force of $104 \mathrm{lb}(47 \cdot 2 \mathrm{~kg})$ was required.

\section{Comment}

High density polyethylene plates are of particular value when the bone is soft or a fracture is comminuted. They have been used most often in combination with a metal plate in the management of elderly patients with supracondylar or trochanteric fractures of the femur. Not uncommonly in these cases a metal plate distracts from the lateral aspect of the shaft when the patient starts to walk, ${ }^{2}$ and a number of patients in whom this occurred have had a second operation at which a high density polyethylene plate was applied to the medial cortex of the bone. This provided rigid fixation and enabled the patients to walk while the fracture healed, thus hastening their return home. I now use high density polyethylene plates at the first operation in patients with osteoporosis or when the screws for any reason fail to obtain a firm hold in the bone.

The plates are made by Zimmer (Orthopaedic) (GB) Limited and a provisional patent application (No 13367/75) has been filed. They were originally developed in the Orthopaedic Research Departments of the Royal East Sussex Hospital, Hastings, and the Redhill General Hospital, Surrey. I am grateful to $\mathrm{Mr}$ W $\mathrm{T}$ Bond for doing the distraction tests on the plates.

${ }^{1}$ Devas, M B, and Irvine, R E, fournal of Bone and foint Surgery, 1967, $49 \mathrm{~B}, 186$.

2 Gallannaugh, S C, British fournal of Accident Surgery, 1974, 5, 259. 